\title{
Retinopathy screening and the new politics of prevention
}

With the emergence of structured diabetes management in general practice and the development of integrated care programmes, local medical practitioners had taken their first steps on the road to managed medical practice. A key driver for more expansive systems of care had been the growing emphasis on surveillance and prevention of diabetic complications in medical discourse. Over the 1970s and 1980s, hospital clinicians, GPs, ophthalmologists, and opticians all displayed particular concern with retinopathy (visual impairment and blindness following bleeds in the eye), and the BDA also strengthened its ongoing efforts to improve management of the issue.

Underpinning this interest was new evidence that the timely application of screening and photocoagulation (laser) therapy might prevent visual deterioration in patients with specific types of retinal lesions. Indeed, large-scale studies proved so convincing that diabetes specialists and ophthalmologists lobbied the DHSS during the late 1970s about establishing new centres for retinopathy prevention. Despite a change of government and a simultaneous shift in the trajectory of British politics, over the next decade retinopathy screening and treatment became the subject of much (albeit intermittent) policy discussion within the DHSS. By 1985 the DHSS had approved a trial programme for retinopathy screening and treatment under a Special Medical Development (SMD) grant, one intended to produce future regional standards.

Moving our focus from the clinic to Whitehall, this chapter reconstructs the shifting fortune of retinopathy screening trials within the DHSS, exploring the ways in which political change, financial constraints, and new understandings of prevention enhanced political interest in diabetes and reshaped policy around its management. Following the creation of regional standards for clinics in 1953, diabetes 
failed to generate substantial political interest in subsequent decades, certainly in comparison to other chronic diseases and risk factors with higher mortality rates or more influential lobbying interests. ${ }^{1}$ Various aspects of diabetes care - from prescription charges to special foodstuffs - had been raised in Parliament during the 1960s and 1970s, and the DHSS and MRC had engaged with questions about drug safety. ${ }^{2}$ However, there was little in the way of concerted government programmes or interventions. This changed considerably in the 1980s. The volume of parliamentary discussion increased greatly, as technological innovations and concerns about complications became subject to debate and the limitations of NHS resources. ${ }^{3}$

In part, this chapter argues, the reappearance of diabetes was predicated upon networks of exchange developed over the post-war period. For instance, between the 1960s and 1980s, a plethora of actors including medical specialists, professional and non-governmental organisations, civil servants, Members of Parliament, and ministers interacted to construct retinopathy as a political object. Action was provoked by new evidence about a hitherto marginal clinical technology, but the creation of novel programmes required persistent support and lobbying. Of equal importance to the political fortunes of diabetes, however, were the ways in which policy actors adapted to a changing political environment. The election of a Conservative government in 1979 intensified government dedication to reducing and reallocating state expenditure, posing problems for any potential initiative. In response, between 1977 and 1985, professional organisations and interested civil servants gradually developed bodies of evidence that reframed retinopathy screening and treatment in terms that were more convincing in the new political climate. Increasingly, policy participants stressed screening and photocoagulation therapy as a form of tertiary prevention, and suggested that intervention could reduce health and social welfare spending. As well as being a clinical and moral issue, management of retinopathy aligned with new political imperatives of retrenchment and national competition. It was this focus on preventive medicine and potential savings that attracted ministerial attention to organisational trials. Funding had been in doubt as late as 1983, but fresh political interest in the economic possibilities of prevention set retinopathy in a new light.

In examining these developments, this chapter does more than tell a story of policy networks. ${ }^{4}$ Although the trials in question were not the most significant government intervention into diabetes management, 
tracing the tribulations of DHSS support enables us to explore how diabetes was politicised by the professional connections and changing conceptions of preventive health discussed in earlier chapters. Moreover, the work of influential organisations and dogged civil servants, like those discussed here, had longer-term impacts, with diabetes constructed as an object of prolonged interest to British governments. In the years after 1985, successive administrations engaged with diabetes management as a clinically and financially important concern. In the political arena, diabetes management itself was simultaneously transformed into a clinical and public health act, one which provided a promising laboratory for practices of clinical governance, service management, and NHS reform. Finally, in telling the story of central government interest in retinopathy, this chapter also begins to trace the importance of international conditions and British neoliberal politics to diabetes management, concerns that are taken up in Chapters 5 and 6. Before we can give this interest meaning, however, we must first understand how retinopathy emerged and developed as a medical concern.

\section{Retinopathy and the clinic at the mid-century}

Discussions of retinal changes in diabetes were commonplace in medical discourse by the 1950s. ${ }^{5}$ Doctors practising in the late nineteenth century had first proposed the possible existence of a discrete 'diabetic retinitis' following the development of the ophthalmoscope. ${ }^{6}$ However, the existence of similar lesions in other conditions - particularly the renal and arterial pathologies then common in older patients with diabetes - undermined consensus about whether specific ocular changes occurred in diabetes until the 1930s. ${ }^{7}$ The development of insulin therapy provided the grounds for clinicians to resolve their disputes, as retinopathy was gradually noted in younger patients without associated pathologies, and specialist clinics concentrated patients for more refined research. ${ }^{8}$ Doctors continued to disagree about the possible causes of retinopathy, a debate that became entangled with wider disputes about the relationship between long-term metabolic control and the onset of diabetic complications. ${ }^{9}$ Nonetheless, medical agreement about the distinctiveness of diabetic retinopathy had been reached by the mid-century, and textbooks dedicated considerable space to describing characteristic pathological changes.

Retinopathy itself, mid-century doctors noted, involved different types of lesion in the eye. Microaneurysms (swelling of blood vessels), 
neovascularisation (growth of new blood vessels), and exudate (oozing fluid) of differing character were of special interest, and clinicians suggested that visual impairment followed from haemorrhages into the vitreous humour (the jelly substance between retina and lens). This bleed might clear after causing initial impairment. Nonetheless, clinicians read this development as a portent that further bleeds would ultimately result in permanent opacity and blindness, despite also admitting that the unpredictable course of retinal changes made prognosis and therapeutic assessment difficult. ${ }^{10}$ In fact, although specialists remarked on the commonality of patients with retinopathy after the 1930s, by no means did the vast majority of patients go blind. ${ }^{11}$ In the mid-1970s, for instance, one textbook estimated that 7 per cent of patients with diabetes for over thirty years would experience a loss of sight, and that 'in the majority of diabetics with retinopathy sight is unaffected. ${ }^{12}$

Irrespective of such statistics, both patients and doctors feared finding retinopathy. For instance, one interviewee (diagnosed in 1973) remarked that she had remained on a strict dietary regimen for over thirty years because 'I am always terrified of going blind or losing my feet or something. ${ }^{13}$ Clinicians also admitted complex feelings towards retinal changes before the late 1970s. One doctor, for example, spoke of his 'dread' of the complication, whilst others admitted a sense of 'helplessness' in the presence of degenerative pathology. ${ }^{14}$

It was this 'helplessness in the face of progressive eye disease', one textbook suggested, 'rather than ... confidence in treatment', that led to recommendations of 'drastic procedures. ${ }^{15} \mathrm{~A}$ fatalism surrounded retinopathy during early post-war decades. 'In practice', wrote one authority, 'few would have the courage to neglect strict control as a part of the treatment of retinopathy although it clearly has no striking effect if any on the course of the disease. ${ }^{16}$ Yet the alternatives to strict control were often risky and of uncertain value. ${ }^{17}$ On the one hand, doctors during the 1950s and 1960s experimented with dietary and pharmacological attempts to lower blood lipids, believing that retinopathy was connected with arteriosclerosis. Such efforts were often found to have inconsistent effects, and visual improvements were not demonstrated. ${ }^{18}$ On the other hand, doctors and patients could turn to more radical interventions, most prominently pituitary ablation (hypophysectomy) or adrenalectomy. Although the effects in some young patients could be stark, these treatments held the inherent risks of dramatic surgery. One symposium on hypophysectomy held in 1962 indicated an 11.2 per 
cent postoperative death rate ( 15 of 134 cases), with a further 29 per cent of patients dying after six years ( 39 of 134 cases). ${ }^{19}$ Beyond mortality, surgery also had significant side effects, such as worsening hypoglycaemia, impotence, and the reliance on replacement therapy. Aware of the dangers and uncertainties, senior British doctors were seemingly reluctant to use these more drastic interventions. Whilst some avoided them completely, others considered for surgery only those 'rare' patients whose retinopathy had met the possible criteria for intervention: 'young people in which new vessels rapidly sprout up all over the retina and, untreated, lead to blindness within a year. ${ }^{20}$ In other words, before the late 1970s, doctors considered 'prevention ... difficult and treatment unsatisfactory.'

\section{Politicising treatment: retinopathy, photocoagulation, and the BDA}

One treatment for retinopathy that had been experimented with, and often dismissed, during these early post-war decades was photocoagulation. The first tests with light-focused therapy had taken place in Germany during the 1950s. The practice cauterised new vessels, with the aim of preventing the haemorrhages that produced visual impairment. ${ }^{22}$ By the early 1970s, thousands of photocoagulation procedures had occurred internationally, but in Britain (as elsewhere) as late as 1972 ophthalmologists still suggested that 'the place of light coagulation in treating retinopathy remained doubtful. ${ }^{23}$ It was the emergence of new studies in the 1970s that altered this perception, and in Britain the BDA used the results to politicise screening and treatment as a moral imperative.

As noted in earlier chapters, large-scale trials and epidemiological studies came to play an increasingly important role in medical epistemology over the initial post-war decades. ${ }^{24}$ Clinical experience and judgement remained integral parts of medical knowledge, and GPs stressed the importance of knowing patients as individuals. ${ }^{25}$ Moreover, trial results did not translate easily into practice given the artificiality of study protocol, and the data (and interpretations) of different studies could conflict. ${ }^{26}$ Nonetheless, academic doctors in particular placed a strong emphasis on universalisable, statistically validated evidence (alongside other forms of basic scientific research) in debates about medical truth, treatment, and disease causation. ${ }^{27}$

Thus, when a large-scale American trial of photocoagulation therapy for diabetic retinopathy published its findings during the mid-1970s, 
British doctors were quickly convinced of the technology's efficacy, despite earlier reservations. Within a changing epistemological landscape, the trial's methodological innovations proved crucial to its acceptance. Firstly, the study was predicated upon a standard definition of retinopathy, produced by respected participants. The reputation of the architects secured external credibility, whilst standardisation enabled large-scale co-ordination between practitioners, and comparison between and subjects. ${ }^{28}$ Secondly, with increasing importance being attached to case-controlled studies in scientific debates, the trial's employment of single-eye treatments - which constituted a subject's second eye as a control - proved convincing. ${ }^{29}$ The study was thus able to alleviate previous uncertainties over whether individually variable natural remissions affected outcome more than treatment. Undertaken in cases with severe 'background' retinopathy and proliferative changes, the trial indicated that photocoagulation would 'approximately halve the risk of catastrophic visual loss' when it reported towards the end of the 1970s, and the findings found support from influential figures and publications in British medicine. ${ }^{30}$

Results from contemporaneous trials in the UK supported the American findings, and the new evidence raised pressing ethical and political questions. ${ }^{31}$ As one prominent clinician and member of the BDA, Arnold Bloom (Whittington Hospital, London), put it in the Lancet: 'it has now been demonstrated that photocoagulation is effective in delaying visual deterioration in some types of diabetic retinopathy. This being so, we have a plain duty to make available this treatment to all diabetics who can benefit from it. ${ }^{32}$ But, as the reference to 'some types' of retinopathy made clear, these trials indicated that treatment would benefit only patients with particular retinal changes. ${ }^{33}$ Given the speed and unpredictability of these changes, both the medical press and senior figures like Bloom pointed out that new screening and surveillance arrangements would be necessary. ${ }^{34}$ Finding and monitoring the 'higher risk' population would offer the best possibility of detecting problems at their earliest stage, as well as fulfilling another ethical aim: avoiding harm to patients who could not be helped by removing them from consideration. ${ }^{35}$

These moral imperatives had political implications within a collectivised system. During the late 1970s and the 1980s, the resources and expertise to conduct screening and treatment were in short supply. ${ }^{36}$ Interlocutors on the issue had already conceded that the new evidence demanded a redistribution of tools, personnel, and activity, a process 
that could often be intensely fraught. ${ }^{37}$ Nonetheless, questions remained about the most effective form of organisation, and it soon became clear that extra resources might be required to establish an efficacious and equitable system within the NHS. Political authorities would need to be engaged.

One party interested in recent therapeutic developments was the BDA, which, along with British ophthalmologists, had co-ordinated the UK photocoagulation studies. ${ }^{38}$ The BDA had long been interested in the problems of blindness, and had established its own Committee on Blindness to consider issues of prevalence, incidence, clinical management, and social services between 1967 and 1969. ${ }^{39}$ Once again international connections were important. The BDA established the Committee following resolutions on blindness passed at the 1967 congress of the International Diabetes Federation, a body composed of representatives of national diabetes associations from across the world. ${ }^{40}$

In terms of later political work, however, the Committee's report is notable for two reasons. Firstly, the report heavily revised existing estimates of blindness due to diabetes. Feeling that official methods of assessment (based on registrations for welfare services) underplayed the prevalence of diabetes-related blindness, the Committee conducted a sample survey of diabetic clinics. The results nearly doubled estimates of prevalence (to around 5,700 individuals), amplifying the size of the problem and introducing demographic disaggregation by identifying retinopathy as the leading cause of blindness in women during their seventh decade. ${ }^{41}$ Later research would refine demographic arguments to produce considerably more noticeable claims, but the medical press reported the increased estimates of retinopathy-related blindness. ${ }^{42}$

The second notable part of the Committee's report was the national network of institutions from which it emerged. The Committee received evidence from the DHSS, the Central Office of Information, and the Government Social Survey, and had close connections with the Royal National Institute for the Blind. ${ }^{43}$ In addition, we have already noted how BDA involvement in trials had forged connections with leading ophthalmologists. The co-operation from such bodies speaks to a broader point about the BDA's authority on diabetes management in Britain. The organisation had a considerable professional membership, and its mix of annual events and support for research enabled doctors and epidemiologists to forge important connections. ${ }^{44}$ Beyond the profession, the Committee's work reveals how the Association's influence also spread to central government departments. The DHSS and other 
state-funded bodies were aware that policy decisions about diabetes would ideally have Association input. This is not to say that relations between such agencies were always cordial. For instance, during a long and tortuous attempt to establish a trial on the safety and efficacy of oral hypoglycaemic drugs, the MRC had predicted 'trouble' with the BDA from the start, whilst senior figures in the Association spoke in frustration of delays and the continued 'digest[ion]' of proposals 'by the bureaucrats. ${ }^{45}$ Nonetheless, perhaps more telling of the BDA's position was the admission by the MRC and DHSS that that they 'would need full BDA cooperation if the trial is to be successful. ${ }^{46}$ It was a sentiment that neatly indicated the extent of the connections based on the Association's moral and scientific authority.

Establishing retinopathy as a political problem: diabetic eye centres and the DHSS, 1976-1977

Following the American and British trial results, the BDA and senior British ophthalmologists worked to establish retinopathy screening and photocoagulation as concerns for the DHSS. Diabetic retinopathy had appeared indirectly in parliamentary discussion in June 1976, when a question about government research on causes of blindness revealed MRC and DHSS funding for investigations on specific forms of retinopathy. ${ }^{47}$ The BDA, however, made more substantive moves on screening and photocoagulation during 1977. Its Medical and Scientific Section held a symposium on the subject in March, attended by the most influential figures in diabetology from across the country. Here, a unanimous decision was taken to initiate further collaboration with ophthalmologists and the DHSS in a bid to establish 'Regional Diabetic Eye Centres' (DECs) across Britain. ${ }^{48}$ In preparation, two senior figures in the fields of diabetology and ophthalmology, Dr Arnold Bloom and Mr Rolf Blach (Moorfields Eye Hospital, London), sent letters to all the RHAs and the most significant ophthalmologists and diabetic departments. They enquired about the possibility of establishing such centres, where they might be located, and what resources would be needed. ${ }^{49}$ In general, the RHAs forwarded the letters to their medical advisory committees, and senior medical figures responded favourably to the proposals for centres. All, however, commented on the need for extra finance and staffing for plans to be put into practice. ${ }^{50}$ Some correspondents indicated that photocoagulation had been discussed already within various fora, including doctors making contact with the DHSS. 
The extent to which this action was independent of the BDA, though (given its professional membership), is uncertain. ${ }^{51}$

The final step in these early moves around photocoagulation treatment involved the Faculty of Ophthalmologists (at this time, one of two professional organisations for ophthalmologists in Britain) contacting the DHSS to 'assess the provision of facilities following the publication of [a] leading article in the Lancet' (mentioned above). ${ }^{52}$ In response, the DHSS called a meeting of leading specialists in diabetes and ophthalmology in November 1977, and the issue of retinopathy treatment also appeared (albeit in a non-committed manner) in the White Paper Prevention and Health, published at the end of December $1977 .{ }^{53}$ By late 1977, therefore, key specialist bodies, a lay-professional organisation, and influential practitioners had formed connections with interested civil servants, and the issue was of demonstrable practical concern within health authorities and their medical advisory committees. DECs now became of political interest. ${ }^{54}$

The basis of the first DHSS meeting on retinopathy and photocoagulation was a position paper produced by the chair, Dr G. Pincherle, a Senior Medical Officer in the DHSS and a person with diabetes. ${ }^{55}$ Although not explicitly framed in ethical terms, the paper presumed that new evidence about the preventive and ameliorative powers of photocoagulation had created a new 'need', and that the DHSS should assist in some way. ${ }^{56}$ On this basis, Pincherle set about estimating the possible extent of the problem, and the potential labour requirements for meeting any increase in workload. His paper succeeded in highlighting a significant lack of information on the issue. The paper cited no epidemiological or clinical surveys, and instead used registrations of blindness and estimates of diabetes' prevalence in England and Wales to assess resource requirements. With the labour divided between thirty to forty centres, Pincherle estimated that the work would require one to two whole time equivalent (WTE) staff per centre, with most staff being new appointments trained in the requisite techniques. ${ }^{57}$ Pincherle made clear, however, that the meeting and paper would not signify a government commitment, and no new resources would be found centrally. Instead - declaring that the work would probably cover areas established under the 1976 planning and priorities system Pincherle indicated that health authorities could reasonably be expected to bear the burden. ${ }^{58}$ The purpose of the meeting would be to assess the estimates made and talk further about resource requirements, as well as to discuss possible changes in organisation, training, and staffing 
(such as the use of general ophthalmic service opticians, rather than consultants).

The meeting followed the pattern Pincherle laid out. New BDA figures about the incidence of diabetic retinopathy were introduced, and the Association's estimates of need (screening all 1 million people with diabetes, twice a year) and required personnel (100 WTE staff initially, 36 after backlog) were considerably larger than those in the DHSS paper. Following this, discussion then turned to who should conduct screening, with participants disagreeing about the abilities of ophthalmologists, physicians, and opticians. Both sides of the debate agreed, nonetheless, that the contrast between the monotony of the work and the need to maintain vigilance meant that the workload should be shared to prevent mistakes. Moreover, all participants concurred with the BDA's position that specialist DECs were necessary, and should receive referrals from clinics, GPs, and ophthalmologists without requisite equipment. In other words, the meeting demonstrated considerable interest in questions of organisation, management, division of labour, and hierarchy, which, as previous chapters have shown, were being worked out elsewhere in diabetes care and British medicine.

The main outcome of the meeting was that DHSS staff committed themselves to 'look favourably on applications for research grants to assist the establishment of 2-3 pilot centres as a means to assessing the most suitable means of organising ... a service. ${ }^{59}$ The findings would influence debates about training, and it was noted that if the pilot schemes showed that a change in [position] was desirable' then the Special Advisory Committee 'would no doubt give serious consideration' to incorporating screening skills into the 'basic training for consultants. ${ }^{60}$ It was on the basis of funding two or three demonstration centres that an administrative civil servant in the meeting forwarded on plans for SMD funds within the DHSS. In light of straitened finances, the plans stressed careful site selection, proposing to establish test centres 'within hospitals which already specialised in the treatment of diabetic eye conditions'. In this way, an 'extremely worthwhile candidate for SMD funds' would require only a 'very modest bid."

The support for SMD funding of pilot DECs at this juncture should not be a surprise. Firstly, the parlous state of government finances during the late 1970s made retinopathy prevention enticing, but ruled out more extensive options. The government's need to ease anxious capital markets and maintain a stable currency undermined room for policy manoeuvre, with drastic expenditure cuts compounded by 
conditions attached to an International Monetary Fund loan in $1976 .{ }^{62}$ In such conditions, preventive medical activity became of interest 'both on humanitarian and economic grounds', though only limited resources were available for innovation. ${ }^{63}$

Secondly, the BDA was well represented in the meeting. Amongst the attendees were five ophthalmologists (including $\mathrm{Mr}$ Blach) and two diabetologists (Professor J. Malins, along with Dr Bloom), with at least five of the eight medical and surgical invitees connected to the BDA. ${ }^{64}$ Crucially, as we have seen, these individuals had also been a part of high-level discussion within the Association, and promoted regional organisation in the medical press. They had therefore helped construct the BDA's position on DECs, which was upheld in the meeting and which remained steady over the following five years.

Finally, Labour Party policy on the NHS also meant that DHSS staff were attracted by DECs. The perceived predominance of retinopathy amongst the elderly dovetailed with the new priorities and planning system. Furthermore, the potential position of 'the region' in screening and treatment proved important. Although heavily questioned within NHS reform debates, regional machinery had emerged relatively unscathed from the 1974 NHS changes, and RHAs were central to priority-setting and planning. ${ }^{65}$ The idea of regionally organised centres aligned neatly with the politics of the health service at this time, and with the old tradition of technocratic planning within the DHSS. ${ }^{66}$ The DEC plan thus gained traction with interested officials, who felt 'one of the attractions at our meeting the other day was the prospect of getting this going in the Regions. ${ }^{67}$ Such favourability did not mean that interested DHSS officials were willing to back any potential applicant. The DHSS received several proposals for DEC funding towards the end of the 1970 s that officials deemed inappropriate for support. ${ }^{68}$ Nonetheless, this civil service investment proved crucial to the survival of SMD applications during a change of government, even as party policies moved the goalposts for officials.

\section{DECs, neoliberalism, and SMD funding, 1979-1984}

Despite support within and without the DHSS, initial discussions over DECs did not lead to earmarked funds for the following year. ${ }^{69}$ Almost as soon as momentum for DECs was building, the political and policy context within which advocates for DECs had to function changed considerably. 
The general election of 1979 returned the Conservative Party to government, and installed Margaret Thatcher as Prime Minister. Early academic analyses cast the policies and rhetoric of Thatcher's subsequent administrations (1979-90) as an 'end of consensus'. This work suggested that, after 1979, retrenchment and a policy dedication to individualism and free market economics replaced a cross-party, crossWhitehall policy paradigm which had been forged after the Second World War, built around state intervention in industry and a Keynesian commitment to full employment, as well as generous support for a social wage and the welfare state. ${ }^{70}$ Such assessments were consciously put forward by Margaret Thatcher herself, and were in part derived from the critique espoused by leading Conservative figures from 1974 onwards. ${ }^{71}$ After the mid-1970s, Thatcher, along with Sir Keith Joseph, vigorously attacked 'the state', its socialist architects, and an undemocratic corporatism with unions as the causes of Britain's ills. ${ }^{72}$ State responsibility, they proposed, sapped Britons of their self-discipline and entrepreneurial initiative; robbed individuals and families of choice over schools and parenting; created corrosive 'dependency' amongst social security recipients; failed to confront criminality and delinquency; 'crowded out' businesses from wealth-creating activities; and provided the conditions in which markets - crucial moral and economic technologies - could no longer function. ${ }^{73}$

Although acknowledging that considerable shifts in policy and political discourse took place, scholarship since the 1990s has queried earlier assumptions of consensus or political revolution. These accounts have highlighted significant policy disagreement, change, and opportunism (rather than conviction) before and after 1979. ${ }^{74}$ Such work has doubted the extent to which Keynesianism, planning, or economic corporatism had ever been consistently or effectively applied, as well as tracing policies and rhetoric around economic freedom across the post-war period. ${ }^{75}$ Likewise, just as the three decades after 1945 were not truly marked by consensus, the two decades after 1979 were not quite as radical as some scholarship would suggest. ${ }^{76}$ Conservative administrations certainly incorporated neoliberal analyses into policy-making: critiques of state and economy within which competition and enterprise are considered the most efficacious forms of allocating resources and guaranteeing individual freedom. ${ }^{77}$ Yet, rather than supporting efforts to 'roll back the state' per se, neoliberal rationalities prompted the creation of an interventionist architecture of monitoring and regulation in the name of competition. ${ }^{78}$ Efforts to denationalise industries or 
introduce market-like mechanisms into welfare services rarely translated into complete freedom from government intervention, and the distance between planning and management practices was perhaps not as great as might have been expected.

This is not to say that the political situation in Britain was unchanged after 1979. Under the Conservatives many areas of policy - from industry and union regulation to social security, finance, and local government - experienced considerable transformation. ${ }^{79}$ Nonetheless, some policy modifications had a longer trajectory than a change of government, and many interventions were adjusted considerably in implementation. ${ }^{80}$ Equally, the profound social and economic transformations of post-war Britain - as well as the development of government policies - had as much to do with broader international climate, long-term social and cultural trends, party-political strategy, non-governmental organisations, ministerial personalities, and other influences as they did with the Conservative government's particular ideological predilections. ${ }^{81}$ Considerable political shifts occurred, but change was rarely as systematic or as ground-breaking as an earlier literature has suggested. ${ }^{82}$

In terms of DECs, along with professional, BDA, and civil service support, the fate of SMD funding was tied closely to shifts in health policy, especially political orientations to welfare service oversight and government spending. The period between 1979 and 1982 witnessed little discussion of SMD funding, even though exchange over trial centres continued. For instance, DHSS officials were in constant contact with the BDA, specialists, and authorities who might potentially house trial DECs. ${ }^{83}$ They even brought the problem of retinopathy to the attention of new ministers where possible. ${ }^{84}$ Responses to a number of enquiries at this time, however, indicated that attitudes to funding and provision were influenced by a broader government policy of decentralisation in the health services. ${ }^{85}$ Partially mirroring the approach taken under the previous administration, DHSS civil servants could offer encouragement to bodies looking to establish specialist screening and treatment services, but no more. Funding decisions were for local authorities, as was made clear in government correspondence and parliamentary replies on issues of retinopathy and diabetes management. ${ }^{86}$

This policy disposition slowly changed after 1982, alongside government interest in NHS managerial reform, but parties interested in SMD funding still faced problems of state finance. ${ }^{87}$ On the one hand, there was the issue of spending constraints. Despite intended budget cuts, 
government expenditure rose in real terms almost every year during Thatcher's premiership. ${ }^{88}$ However, spending decreased as a proportion of GDP, and real-terms figures probably reflected shifting demographics and uneven expenditure. Increases in unemployment and retirement, for instance, meant that rising social security payments offset deep cuts elsewhere, and much of the safeguarded NHS expenditure for the early 1980 s funded wage increases rather than services. ${ }^{89}$ In other words, successive administrations sought to reduce spending on activities that they deemed ineffective or iatrogenic. Although not a high-spending area, DHSS-funded research felt the pinch: as Dr Pincherle explained to colleagues in 1982, initial efforts at pilot studies for retinopathy screening and treatment were 'victims of cuts in research budget [s].9

On the other hand, as well as imposing financial restraints, the Conservative governments of the 1980s also sought to reform how money was allocated. For a host of individual social security benefits, Conservative administrations expanded extant administrative procedures (such as means testing), introduced taxation and new eligibility criteria, and altered cost-indexing to reverse, freeze, or slow increases. ${ }^{91}$ These changes in allocative practices were also applied systemically, encouraged by shifts in political discourse and institutions outside the Conservative Party leadership. The Thatcher administrations allied cash-limited budgeting (introduced to departments under previous Labour governments) with more intense programme review analyses; at the same time, parliamentary reforms of select committees encouraged more rigorous monitoring of the effects of government spending. ${ }^{92}$ Policy drives to reallocate government intervention, and increase competition and labour mobility, therefore, were supported by old Treasury concerns about government expenditure and broader emphases on value for money.

It was in this context that DEC planning received a boost in the summer of 1982. In August, Wallace Foulds, Professor of Ophthalmology at the University of Glasgow, sent Pincherle, and contacts at the Scottish Home and Health Department (SHHD), a pre-publication paper on retinopathy prevalence and incidence, with particular focus on the potential costs of a screening and treatment programme for the west of Scotland. ${ }^{93}$ Demonstrating the ways in which personnel and research moved across Britain as a whole, Foulds had participated in the initial DHSS panel to discuss DECs in 1977..$^{4}$ The networks of interested parties supporting DECs before 1979 had thus held fast, ensuring broad support for the idea across the intervening period. 
Moreover, the interconnected structure of British medicine and administrative machinery ensured that, whilst the Scottish health services were in many respects distinct from those of England and Wales, the boundaries separating the NHS's constituent elements could easily be crossed in the right circumstances. ${ }^{95}$

Between the consultation meeting in 1977 and Foulds's paper in 1982, DHSS officials had become aware of numerous publications and projects on retinopathy and its detection and treatment. ${ }^{96}$ Foulds's paper, however, was the first substantive piece of work seen by officials that drew together large-scale investigation of prevalence and incidence with costed comparisons of tests, screening staff, and equipment. ${ }^{97}$ One medical civil servant who received the paper even suggested that it was 'one of the most exciting [papers] in practical terms I have seen in some time' and exactly 'the sort of health services research we need more of. ${ }^{\text {' }}{ }^{8}$

To some extent, the paper confirmed findings from smaller-scale projects and the previous 'best guesses' made by DHSS staff. ${ }^{99}$ From a sample of around 1,200 patients, the study estimated the prevalence of different types of retinopathy at 30 per cent, with 10 per cent of people with diabetes estimated to have retinopathy serious enough to go blind. (This was similar to the proportion estimated in 1977, though for different reasons.) Foulds's team found a fresh incidence of retinopathy to be around 5.5-8 per cent, estimating that around 1.2 per cent of patients would have serious cases. ${ }^{100}$ At the same time, marking a more overt recognition of economic arguments in motivating change, they noted that 'diabetic retinopathy was the leading cause of blindness in the age groups 20-44 and 45-64[,] underlying the important economic fact that diabetic blindness is the commonest cause of blindness amongst those of working age. ${ }^{101}$ Extrapolating these figures to the west of Scotland region (2.5 million population), the paper then estimated the likely workload for a new system that screened 25,000 people diagnosed with diabetes ( 1 per cent prevalence) annually. In the first two years, the programme would encounter a backlog of 8,300 patients with retinopathy, of which 2,500 would have serious cases and 1,250 would be treatable. Once these were cleared, the authors then expected to find 300 patients with serious retinopathy per year, of which 150 would need laser therapy. ${ }^{102}$

The respective methods applied to calculating staffing requirements in the Foulds and Pincherle papers make their estimates incomparable. More important for the DHSS staff, however, were Foulds's estimated comparative costs of the scheme if different workers were to undertake 
Table 4.1 Estimated costs of different screening modalities

\begin{tabular}{lcccc}
\hline Staff screening & $\begin{array}{c}\text { Cost per } \\
\text { person } \\
\text { screened }\end{array}$ & $\begin{array}{c}\text { Cost per } \\
\text { patient } \\
\text { identified }\end{array}$ & $\begin{array}{c}\text { Cost per } \\
\text { patient } \\
\text { treated }\end{array}$ & $\begin{array}{c}\text { Cost-benefit } \\
(£)\end{array}$ \\
\hline Physicians & $£ 2.30$ & $£ 193$ & $£ 387$ & $1: 3.3$ \\
Hospital opticians & $£ 1.20$ & $£ 99.40$ & $£ 199$ & $1: 6.5$ \\
General ophthalmic & $£ 6.84$ & $£ 570$ & $£ 1,141$ & $1: 1.1$ \\
$\quad$ service opticians & & & & \\
\hline
\end{tabular}

Source: TNA, final report, 'An investigation of the prevalence of diabetic retinopathy'.

screening and treatment. ${ }^{103}$ The paper even estimated the total savings in social security arising from preventing blindness through screening and treatment, and provided cost-benefit ratios for each possible alternative. For physicians as screeners, for instance, $£ 3.30$ would be saved from social security for every $£ 1$ spent (see Table 4.1). Added to these were psychological and social losses to blindness that 'cannot be assessed in economic terms', and the potential earnings (and thus tax revenue) of now employable non-blind persons. ${ }^{104}$

Taken on its own merits, the new paper possessed several logical and practical limitations, given its extrapolation from one small sample to a much larger presumed population. However, within the context of the Conservatives' fiscal management, the considerable excitement amongst DHSS officials is understandable. Almost immediately upon receipt, DHSS staff re-engaged with the SMD grant proposals that they had begun to draw up in 1977. Pincherle forwarded the evidence to colleagues, who recommended preparing a paper for ministers. ${ }^{105}$ Pincherle also arranged a meeting of DHSS officials in December 1982 and prepared a fresh paper to present. Reflecting the intensified emphasis on economy within central government, this paper was written with advice from the Economic Advisers' Office. ${ }^{106}$ Although health economics did not always prove influential in service reform, the input of economists - and languages of costs and savings - were important here ${ }^{107}$ The new paper broadly used Foulds's figures for incidence and prevalence, but extrapolated for the whole of the UK, and estimated a higher rate of treatability on the basis that regular screening would catch problems 
earlier. ${ }^{108}$ The meeting, which included input from the DHSS Ophthalmological Consultant Adviser, made no considerable alterations to Pincherle's paper, and participants mostly discussed issues of personnel (ratio of staff to patient population, suitable work to be undertaken). ${ }^{109}$ With a broad consensus reached, the meeting endorsed Pincherle's suggestion to contact the Finance Division to discuss funding.

The financial prospects did not initially appear favourable. In October 1982, staff received a memo on Centrally Reserved Funds (including those for SMD), which spoke of the assessor's 'generally unfriendly attitude to centrally financed services in the current climate. ${ }^{110}$ After receiving notification that a bid might be made in July 1983, a DHSS advisor 'counsel[led] caution in going very far at this stage in working up detailed bids'. The author cited 'the Chancellor's statement on public expenditure reductions', and remarked that 'when Ministers come to consider bids for central funding there is likely to be very little room to manoeuvre'. In so doing, the correspondent did not seek to close the door on opportunities 'if [a bid] can be demonstrated to be a potentially cost-effective use of central funds'. Rather, 'what it does mean', they concluded, 'is that it would probably not be sensible, or at least it would run the risk of generating false expectations and wasting effort, if work was done at this stage ... [preparing] schemes which are critically dependent on central support.'

Whilst Pincherle did not significantly alter the proposal paper in response, pressure from financial advisors had been anticipated in early drafts of associated documents. A cover note on 'diabetic retinopathy', for instance, repeated Foulds's claims about the epidemiology of blindness, stressing that 'diabetic retinopathy is the most common cause of registered blindness in the 16-64 age group. ${ }^{112}$ A revised paper took references to labour market loss even further. It added that diabetic retinopathy accounted for 'some 2,100 people in the economically active age group becoming blind each year', but that prevention would save on social security 'payments and special facilities for the blind which will [now] not be required. ${ }^{113}$ Moreover, speaking specifically to health service concerns, it suggested that even the NHS might save money. Pincherle was careful not to commit the DHSS to any larger programme, noting how 'any adoption by health authorities of the results of this study, if successful, must of course be a further call upon their resources. ${ }^{\prime 14}$ However, by operating more efficiently in the process of screening, he suggested that immediate savings would accrue, and 
a good service would also gradually free up beds otherwise taken by blind persons.

The discursive frameworks for the study, in other words, were subtly different in tone from those of the late 1970s. Whereas talk had previously been of need, with some reference to economic benefits of prevention, now there was substantial discussion of cost-effectiveness and social security savings. The previous Labour administration had become increasingly interested in such matters when confronting economic turbulence. However, the Conservative government's ideological principles saw it pursue expenditure reductions much more vigorously, and it demonstrated considerable interest in social security reductions, especially during $1982-83 .{ }^{115}$ As one medical civil servant declared after receiving the Foulds paper: 'The humanitarian aspect [of improving facilities] is important and continuing' as it had been in earlier years. But the Foulds paper motivated new action because, the official noted, 'for a change and a bonus establishing a programme could actually save money'. ${ }^{116}$ Moreover, this focus consolidated views of diabetes management as preventive health practice, ideas which had been discussed in the 1977 White Paper but which did not link to firm action. ${ }^{117}$ Neither the control of diabetes nor even avoiding its associated pathologies was of issue here. Retinopathy of some form already had to be present to trigger intervention. Discussions thus centred upon the tertiary prevention of disability. Equally, in linking prevention in diabetes management to costs and savings in the health and social services, the new framework around retinopathy screening programmes also connected health services management with chronic disease control and public health medicine (see Chapter 6).

This is not to deny the influence of other political concerns. The cover note made it clear that inaction might produce very visible and unwelcome inequalities, resulting in 'uneven service development across the country'. Furthermore, 'in this particular case - preventable blindness', the paper warned that 'failure to take an initiative would be particularly embarrassing to both Ministers and this Department. ${ }^{118}$ Though these were seemingly strong words, the tone had been tempered from an earlier draft which suggested that 'where people become blind in circumstances where it need not have happened, they remain a reproach to those responsible, possibly for many years', in contrast to situations where shortages resulted in death. For moral and public relations purposes, the draft thus concluded, 'there does not appear to be the option of doing nothing. ${ }^{119}$ Whilst softening this rhetoric in the final 
draft, officials nonetheless played heavily on images of an uncaring government that probaby had considerable currency amid rising unemployment and economic dislocation. ${ }^{120}$

This reframing of the issue by civil servants and their professional interlocutors appeared to succeed. The proposal eventually gained the backing of the Office of the Chief Scientist, which administered SMD funding and would provide support for project evaluation. At a meeting in August 1983, the Chief Scientist gathered staff from their Office, the Economic Advisers' Office, and DHSS administrative and medical divisions. ${ }^{121}$ Participants noted the foreboding financial advice, but felt that DEC trials would be needed before the DHSS could issue advice on service organisation to RHAs. ${ }^{122}$ The meeting devised study parameters, which would form the basis of an SMD application supported by the Office of the Chief Scientist. The project itself would involve three centres (as suggested in 1977) comparing the organisation, costs, and benefits of four type of screeners: ophthalmologists, diabetologists, hospital-based ophthalmic opticians, and general ophthalmic service opticians. ${ }^{123}$ With this support gained, Pincherle revised the DHSS paper, and a senior administrative official completed the application. This submission passed up the chain and received ministerial backing in April 1984. ${ }^{124}$ Securing additional support from the BDA, the programme was established in 1985, and began reporting its results in $1990-91 .^{125}$

Conclusion: DEC trials, 'New Right' politics, and diabetes

After all the build-up to the DEC trials, the results of the SMD study did not deliver definitive answers. Study centres were established in Sheffield, Oxford, and Exeter, and assessed the sensitivity of different potential screeners (hospital physician, GP, ophthalmic optician) and screening methods in five different patient groups. Ultimately, it was suggested that 'on the evidence' of the studies 'the routine use of any of these screening methods will fail to detect a large proportion of cases with sight threatening diabetic retinopathy. ${ }^{126}$ Equally, the costs for the initial cases found were considerably higher than previous estimates, and the researchers suggested that 'before any policy decisions can be made about a screening programme ... alternative screening strategies need to be evaluated. ${ }^{127}$ By 1995 , there was still no national system for diabetic retinopathy in place, and debate continued about who should provide screening. ${ }^{128}$ 
Regardless, debates about SMD funding formed part of diabetes' return to policy discussion during the 1980s. The creation of a durable policy network around the issue was crucial in this regard. Spurred on by international interest in blindness during the 1960s, and Anglo-American evidence for the effectiveness of retinopathy treatment in the 1970s, medical specialists, professional organisations, and an influential lay-professional non-governmental organisation helped promote the issue to contacts within the DHSS. Behind the scenes, officials retained contact with these agencies, and promoted the cause within the Department prior to ministerial consideration. Figures outside the DHSS were also able to bring forth new evidence bases and promote the issue to the profession and health services. It was a network that spanned Britain, with evidence from Scotland and elsewhere providing momentum to efforts to secure SMD funding for DECs.

Despite the intensity of clinical concern about retinopathy, DHSS support for centres was not easily secured. In a period of financial retrenchment, and shifts in how and where government money was spent, the construction of retinopathy screening within government was crucial. Although economic concerns and disease prevention had been part of discussions before the 1980s, officials responded to growing central concerns about health and welfare expenditure by positioning such issues as the major themes of any debate on retinopathy screening and treatment. By the middle of the 1980s, the second Thatcher administration had also begun to think more seriously about preventive medicine, though the major reforms on this front would wait until the third Thatcher government. ${ }^{129}$ As noted in Chapters 2 and 3, this orientation to prevention followed growing international emphasis on health promotion and primary care, as well as being motivated by potential cost reduction in acute care. Such thinking may have influenced ministerial decisions on SMD funding. The personal staff of the Minister for Health, for instance, questioned officials in 1984 about whether the DEC trial might be included in a press release on preventive medicine innovations within the Department. ${ }^{130}$ On this occasion, DHSS personnel felt it would be too early to make announcements: funding had been secured, but the programme had yet to choose trial sites and recruit professional staff, with effective decisions here crucial to producing meaningful service standards. ${ }^{131}$ Nonetheless, the fact that a pronouncement was considered speaks to how the politics around prevention had made DEC trials attractive. 
It is this fusion of cost-reduction, preventive medicine, clinical care, and health service management that gives this episode in diabetes care significance. By the 1980s, doctors had framed surveillance and treatment of diabetes and its sequelae as preventive, as well as clinical, medicine. On a local level, success in secondary and tertiary preventive efforts had been gradually linked to questions of organisation, integration, and management of care. In terms of retinopathy, we can see how such equations were making their way into central government. SMD funding was predicated upon the idea that, once new evidence was produced, new guidance could be offered to health authorities on the most effective means for dividing professional labour. Research would create guidance to manage healthcare activity, resulting in improved health and cost savings.

The way in which DECs were discussed, and SMD funding granted, was informed by previous changes in the relationship between diabetes, clinical medicine, and prevention between the 1960s and early 1980s. It was also indicative of the way in which organisations like the BDA and Royal Colleges were thinking about diabetes more broadly. As we will see in the following chapters, during the 1980s and 1990s this reframing of relations provided the basis for a new role in healthcare governance for these bodies, and their views were transmitted into government via the networks discussed above.

In terms of diabetes, interested politicians like Dr Roger Thomas (Labour, Carmarthen) raised questions about its management and surveillance in Parliament, to some extent forcing government attention onto the issue. ${ }^{132}$ Yet diabetes' position at the intersection of costreduction, preventive medicine, clinical care, chronic disease, and health service management saw state bodies become interested in the condition as an early testing ground for developing new approaches to managing medicine.

Although not determinative of government direction, neoliberal critiques of welfare were particularly influential here. As noted above, reforms of the health service in the 1980s and 1990s were not implemented according to any blueprint. Nor were they purely 'neoliberal' according to any abstract criteria. However, characteristic of 'New Right' reforms in Britain, these policies did emerge from neoliberal-inspired analyses, and involved considerable transformation of NHS machinery. As a disease already heavily subject to monitoring and management within the health services, diabetes became an interesting testing ground for the new way of governing healthcare. In collaboration with 
leading professional bodies and other interested parties, the state would produce national standards of process, outcome, and audit, which would inform new contracting arrangements. Likewise, national audits would support local measures to ensure functionality and inform ongoing changes. The specific dynamics of these developments will be explored in the next two chapters. The position of diabetes within new government and professional ideas for health service management and public health, however, began with projects like those funded in retinopathy discussed here.

\section{Notes}

1 V. Berridge, Marketing Health: Smoking and the Discourse of Public Health in Britain, 1945-2000 (Oxford: Oxford University Press, 2007); M. Bufton and V. Berridge, 'Post-war nutrition science and policy making in Britain c.1945-1994: the case of diet and heart disease', in D. Smith and J. Phillips (eds.), Food, Science, Policy and Regulation in the Twentieth Century: International and Comparative Perspectives (London: Routledge, 2000), pp. 207-22; A. Mold, “'Everybody likes a drink. Nobody likes a drunk": alcohol, health education, and the public in 1970s Britain', Social History of Medicine, 30:3 (2017), 612-36.

2 TNA, FD 23/1442, 20, memo for Dr Owen, 'Meeting on oral hypoglycaemic agents', 5 October 1972.

3 A keyword search for 'diabetes' in Hansard revealed a notable step change in interest, returning 172 results in the 1960s, 187 hits in the 1970s, and 634 hits in the 1980s: http://hansard.millbanksystems.com/search/ diabetes (accessed May 2017). Issues of technology and complications were considerable talking points.

4 For post-war health policy networks: V. Berridge (ed.), Making Health Policy: Networks in Research and Policy after 1945 (Amsterdam: Rodopi, 2005).

5 The retina is a thin layer of light sensitive tissue behind the cornea, iris, and lens of the eye.

6 C. O. Hawthorne, 'On peripheral neuritis and retinal changes in diabetes mellitus', The Lancet, 154:3970 (1899), 876-7.

7 S. West, 'Notes on diabetic retinits', The Lancet, 183:4728 (1914), 1034-5; R. B. Tattersall, Diabetes: The Biography (Oxford: Oxford University Press, 2009), p. 26.

8 Tattersall, Diabetes, pp. 82-3.

9 'Retinal changes in diabetes', The Lancet, 246:6361 (1945), 114; T. Dornan and S. Vernon, 'Diabetes and the eye', in R. B. Tattersall and E. A. M. Gale (eds.), Diabetes Clinical Management (Edinburgh: Churchill Livingstone, 
1990), pp. 263-6. See the discussion of control and complications in Chapter 2.

10 J. Malins, Clinical Diabetes Mellitus (London: Eyre \& Spottiswoode, 1968), pp. 191-8.

11 Ibid., p. 202; 'High carbohydrate diets in diabetes', The Lancet, 222:5740 (1933), 538.

12 W. G. Oakley, D. A. Pyke, and K. W. Taylor, Diabetes and its Management, 2nd edition (Oxford: Blackwell Scientific Publications, 1975), pp. 119, 127.

13 Interview with Shirley conducted by the University of Oxford, 22 March 2004, available at: www.diabetes-stories.com/interview.asp?UID=4 (accessed April 2017); C. Feudtner, Bittersweet: Diabetes, Insulin and the Transformation of Illness (Chapel Hill: University of North Carolina Press, 2003).

14 Respectively: G. Graham, 'The diet in diabetes', BMJ, 2:4307 (1943), 116; Oakley et al., Diabetes and its Management, 2nd edition, p. 126.

15 Oakley et al., Diabetes and its Management, 2nd edition.

16 Malins, Clinical Diabetes Mellitus, p. 198.

17 Tattersall, Diabetes, pp. 98-100.

18 Malins, Clinical Diabetes Mellitus, pp. 198-9.

19 Ibid., pp. 199-202, esp. p. 199.

20 Oakley et al., Diabetes and its Management, 2nd edition, p. 126; Malins, Clinical Diabetes Mellitus, p. 201.

21 Malins, Clinical Diabetes Mellitus, p. 125.

22 Tattersall, Diabetes, pp. 101-2.

23 'Retinopathy', The Lancet, 299:7758 (1972), 1004.

24 J. Daly, Evidence-Based Medicine and the Search for a Science of Clinical Care (Berkeley: University of California Press, 2005).

25 I. Löwy, 'The experimental body', in R. Cooter and J. Pickstone (eds.), Companion to Medicine in the Twentieth Century (Abingdon: Routledge, 2003), pp. 443-4. See Chapter 2 above.

$26 \mathrm{H}$. Valier and C. Timmermann, 'Clinical trials and the reorganization of medical research in post-Second World War Britain', Medical History, 52:4 (2008), 493-510; J. A. Greene, Prescribing by Numbers: Drugs and the Definition of Disease (Baltimore: Johns Hopkins University Press, 2007), pp. 115-47.

27 J. N. Morris, Uses of Epidemiology, 2nd edition (Edinburgh: E. \& S. Livingstone, 1964); A. L. Cochrane, Effectiveness and Efficiency: Random Reflections on the Health Services (London: Nuffield Provincial Hospitals Trust, 1972). On quantification in medicine: G. Weisz, 'From clinical counting to Evidence-Based Medicine', in G. Forland, A. Opinel, and G. Weisz (eds.), Body Counts: Medical Quantification in Historical and Sociological Perspectives (Montreal: McGill University Press, 2005), pp. 377-93. 
28 Both co-ordination and comparison were essential in securing multiple participating centres, and thus in increasing the power of the study through higher rates of subject enrolment. As Tattersall makes clear, the absence of a standard definition for what was being treated had made drawing conclusions from a mixture of earlier reports impossible: Tattersall, Diabetes, pp. 102-3.

29 'Photocoagulation for diabetic retinopathy', The Lancet, 308:7976 (1976), $77-8$, esp. p. 77.

30 Ibid.

31 Ibid.; Tattersall, Diabetes, p. 102.

32 A. Bloom, 'Photocoagulation for diabetic retinopathy', The Lancet, 308:7978 (1976), 206.

33 E. M. Kohner and P. J. Barry, 'Prevention of blindness in diabetic retinopathy', Diabetologia, 26:3 (1984), 173-9.

34 Bloom, 'Photocoagulation for diabetic retinopathy'; 'Photocoagulation for diabetic retinopathy', p. 78.

35 Though anxiety might arise in some patients as they 'observ[e] the increased interest and activity centred on [their] eyes': ibid. 'Photocoagulation for diabetic retinopathy', p. 78.

36 C. J. Burns-Cox, 'Early detection of diabetic retinopathy', The Lancet, 324:8404 (1984), 693-4.

37 H. Valier and R. Bivins, 'Organization, ethnicity and the British National Health Service', in J. Stanton (ed.), Innovations in Health and Medicine: Diffusion and Resistance in the Twentieth Century (London: Routledge, 2002), pp. 37-64.

38 'Diabetic retinopathy', The Lancet, 296:7682 (1970), 1073-4.

39 Wellcome Library Archive, London (WLA, PP/ASH/A/3, BDA Committee on Blindness 1967-1969, A Report on Diabetic Blindness in the United Kingdom (London: BDA, c.1970).

40 WLA, A Report on Diabetic Blindness, p. 9.

41 Ibid., pp. 10-13.

42 'Diabetic retinopathy', p. 1073.

43 WLA, A Report on Diabetic Blindness, pp. 10-13.

44 J. G. L. Jackson, 'The formation of the Medical and Scientific Section of the British Diabetic Association', Diabetic Medicine, 14:10 (1997), 886-91.

45 Respectively: TNA, FD 23/1442, 5294/17 [29], memo by D.M.G.M. to Dr Godfrey, 'Oral hypoglycaemic agents in the treatment of diabetes', 16 January 1973, p. 2; TNA, FD 23/1442, 39, Medical and Scientific Section, BDA, 'Secretary's report for the year ended the 31st December 1972', undated, p. 1 . The trial had been sparked by British uncertainty over a major US trial, which indicated that oral hypoglycaemic agents might increase mortality: Greene, Prescribing by Numbers, pp. 115-47; Tattersall, Diabetes, pp. 131-5. 
46 TNA, memo for Dr Owen, 'Meeting on oral hypoglycaemic agents'.

47 Hansard, HC, vol. 912, cols. 1186-9, 8 June 1976.

48 TNA, MH 150/953, letter by Dr Arnold Bloom and Mr Rolf Blach, untitled, 1977, 1. On the Medical and Scientific Section: Jackson, 'The formation of the Medical and Scientific Section', pp. 886-91.

49 TNA, MH 150/953, letter by Dr Arnold Bloom and Mr Rolf Blach. As a consultant surgeon, Mr Blach forwent the title 'doctor'.

50 See responses in file TNA, MH 150/953, 'Hospital Eye Service: facilities for the detection and treatment of diabetic retinopathy; proposed pilot project', 1977-84.

51 TNA, MH 150/953, RJH/JMH, letter by R. J. Hutchinson (Specialist in Community Medicine, Yorkshire RHA) to Dr A. Bloom and Mr. R. Blach, untitled, 13 July 1977; TNA, MH 150/953, EMK/FMH, letter by E. Kohner (Senior Lecturer in Medicine, Royal Postgraduate Medical School, Hammersmith Hospital) to Dr A. Bloom, untitled, 9 June 1977.

52 TNA, MH 150/953, 8B, meeting note, 'Facilities for the detection and treatment of diabetic retinopathy', 1977, p. 1.

53 Ibid.; DHSS, Department of Education and Science, Scottish Office, and Welsh Office, Prevention and Health, Cmnd 7047 (London: HMSO, 1977), p. 71.

54 On the importance of post-war lobbying and health policy networks: Berridge, Marketing Health.

55 TNA, MH 150/953, 4B, Dr G. Pincherle, draft discussion paper, 'Facilities for the detection and treatment of diabetic retinopathy', 17 November 1977. My thanks to Professor Roberta Bivins for sharing this biographical information.

56 TNA, Pincherle, draft discussion paper, 'Facilities for the detection and treatment of diabetic retinopathy', pp. 1-4, esp. p. 3.

57 WTE was a unit indicating the workload of a full-time member of staff. As members of the clinical team would not be employed solely for this work, predictions used WTE to estimate costs rather than new members of staff per se.

58 Services for the elderly, children, and people with mental health and cognitive challenges were the initial priority areas: G. Rivett, From Cradle to Grave: Fifty Years of the NHS (London: King's Fund, 1998), pp. 272-5.

59 TNA, meeting note, 'Facilities for the detection and treatment of diabetic retinopathy', p. 1.

60 Ibid., p. 2.

61 TNA, MH 150/953, 5A, memo by N. L. J. Montagu to Mr Mayoh, 'Special Medical Developments: diabetic eye centres', 2 December 1977.

62 P.Addison, No Turning Back: The Peacetime Revolutions of Post-War Britain (Oxford: Oxford University Press, 2010), pp. 270-1. 
63 DHSS et al., Prevention and Health, p. 71.

64 Another prominent diabetes specialist, J. Nabarro, was invited but could not attend.

65 C. Webster, The Health Services since the War, vol. 2: Government and Health Care, the British National Health Service, 1958-1979 (London: HMSO, 1996), pp. 453-579, esp. pp. 507-8, 606-13.

66 R. Klein, The New Politics of the NHS: From Creation to Reinvention, 5th edition (Oxford: Radcliffe, 2006), pp. 1-21, 46-75.

67 TNA, MH 150/953, 9A, memo by N. L. J. Montagu to Dr Pincherle, 'Proposed diabetic eye centre: St George's Tooting', 10 January 1978.

68 For instance: TNA, MH 150/953, 10A, memo by L. B. Hunt to Dr Pincherle, 'Proposal for the establishment of a diabetic regional eye centre at St George's Hospital', 11 January 1978.

69 TNA, MH 150/953, file note by R. Weighton for Dr Pincherle, untitled, 5, 3 March 1978.

70 P. Addison, The Road to 1945: British Politics and the Second World War (London: Pimlico, 1994 [1975]); D. Kavanagh and P. Morris, Consensus Politics from Attlee to Major, 2nd edition (Oxford: Blackwell, 1995).

71 P. Kerr, Post-War British Politics: From Conflict to Consensus (London: Routledge, 2001).

72 R. Saunders, “Crisis? What crisis?” Thatcherism and the seventies', in B. Jackson and R. Saunders (eds.), Making Thatcher's Britain (Cambridge: Cambridge University Press, 2012), pp. 25-42, esp. p. 34.

73 M. Thatcher, 'It's your freedom they hate', Sunday Express, 23 November 1975, Margaret Thatcher Foundation, available at: www. margaretthatcher.org/document/102808 (accessed April 2017); M. Thatcher, 'My kind of Tory Party?', Daily Telegraph, 30 January 1975, Margaret Thatcher Foundation, available at: www.margaretthatcher.org/ document/102600 (accessed April 2017); Sir K. Joseph, speech given at Edgbaston, 19 October 1974, Margaret Thatcher Foundation, available at: www.margaretthatcher.org/document/101830 (accessed April 2017); M. Thatcher, speech given in Derby, 2 May 1975, Margaret Thatcher Foundation, available at: www.margaretthatcher.org/document/102458 (accessed April 2017). See also S. Hall, 'The great moving right show', in S. Hall and M. Jacques (eds.), The Politics of Thatcherism (London: Lawrence and Wishart in Association with Marxism Today, 1983), pp. 19-39; N. Timmins, The Five Giants: A Biography of the Welfare State (London: Fontana Press, 1996), pp. 356-60.

74 Kerr, Post-War British Politics. For economic policy: R. Lowe, The Welfare State in Britain since 1945, 3rd edition (Basingstoke: Palgrave Macmillan, 2005), pp. 125-6.

75 J. Tomlinson, 'Why was there never a "Keynesian revolution" in economic policy?', Economy and Society, 10:1 (1981), 72-87; N. Rollings, 
'Poor Mr Butskell: a short life, wrecked by schizophrenia?', Twentieth Century British History, 5:2 (1994), 183-205; G. O’Hara, From Dreams to Disillusionment: Economic and Social Planning in the 1960s (Basingstoke: Palgrave Macmillan, 2007); N. Rollings, 'Cracks in the post-war Keynesian settlement? The role of organised business in Britain in the rise of neoliberalism before Margaret Thatcher', Twentieth Century British History, 24:4 (2013), 637-59.

76 On 'Thatcherism' and its literature: C. Hay, 'Whatever happened to Thatcherism?', Political Studies Review, 5:2 (2007), 183-201.

77 D. Stedman Jones, Masters of the Universe: Hayek, Friedman, and the Birth of Neoliberal Politics (Princeton: Princeton University Press, 2014); M. Foucault, The Birth of Biopolitics: Lectures at the College de France, 1978-79, trans. G. Burchell, ed. M. Senellart (Basingstoke: Palgrave Macmillan, 2008).

78 Cf. D. Harvey, A Brief History of Neoliberalism (Oxford University Press, 2005).

79 Addison, No Turning Back, pp. 259-314; Timmins, The Five Giants, pp. 369-494.

80 D. Marsh and R. A. W. Rhodes (eds.), Implementing Thatcherite Policies: Audit of an Era (Buckingham: Open University Press, 1992).

81 A. Gamble, The Free Economy and the Strong State: The Politics of Thatcherism, 2nd edition (Basingstoke: Macmillan, 1994); Timmins, The Five Giants, 369-494; Klein, The New Politics of the NHS, pp. 140-86.

82 B. Jackson and R. Saunders (eds.), Making Thatcher's Britain (Cambridge: Cambridge University Press, 2012).

83 TNA, MH 150/953, 23A, memo by Dr Pincherle to Mr Saville and Dr Buxton (DHSS), untitled, 2 December 1980; TNA, MH 150/953, 33A, minutes of a meeting on 8 June 1982, 'Economic appraisal of screening and early treatment of diabetic retinal blood vessel disorders', 9 July 1982.

84 TNA, MH 150/953, 21B, note by A. G. Saville to Dr Pincherle (and response), untitled, 26 June 1979; TNA, MH 150/953, 22A, note by $\mathrm{Dr}$ Pincherle to Mr Godfrey, untitled, 9 July 1979.

85 Klein, The New Politics of the NHS, pp. 96-101.

86 TNA, MH 150/953, 19A, letter by G. Pincherle to Dr M. Hartog (Honorary Consultant Physician, Southmead Hospital, Bristol), untitled, 23 March 1979; Hansard, HC, vol. 32, col. 495W, 24 November 1982.

87 Klein, The New Politics of the NHS, pp. 114-23.

88 R. Chote, R. Crawford, C. Emmerson, and G. Tetlow, IFS Briefing Note 5: Public Spending Under Labour (London: Institute for Fiscal Studies: 2010), pp. 3-4, available at: https://www.ifs.org.uk/bns/bn92.pdf (accessed May 2017).

89 J. Bradshaw, 'Social security', in Marsh and Rhodes (eds.), Implementing Thatcherite Policies, pp. 85-6; Timmins, The Five Giants, p. 385. Spending 
as a proportion of GDP decreased from 48.1 per cent in $1982-83$ to 39.2 per cent in 1989-90.

90 TNA, MH 150/953, 15, note at front of file by Dr Pincherle for Mr Saville, untitled, 7 April 1982.

91 P. Pierson, Dismantling the Welfare State? Thatcher, Reagan and the Politics of Retrenchment (Cambridge: Cambridge University Press, 1994).

92 Timmins, The Five Giants, p. 381; P. Hennessey, Whitehall (London: Fontana Press, 1990), pp. 330-7.

93 TNA, MH 150/953, 35C, final report, 'An investigation of the prevalence of diabetic retinopathy among patients attending a diabetic clinic and the cost effectiveness of its identification and treatment', undated (c.August 1982).

94 TNA, MH 150/953, 35B, letter by Professor W. S. Foulds (University of Glasgow) to Dr G. Pincherle, untitled, 20 August 1982.

95 J. Stewart, 'The National Health Service in Scotland, 1947-74: Scottish or British', Historical Research, 76:193 (2003), 389-410.

96 For instance, see papers listed at 18A and 20A in file TNA, MH 150/953.

97 TNA, MH 150/953, minutes of a meeting on 8 June 1982; TNA, MH 150/953, 57A, memo by Dr Pincherle to Mr Mancini (Economic Advisers' Office), 28 September 1983. Prior discussion with the BDA about comparative screening costs in Stoke Mandeville had proved disappointing.

98 TNA, MH 150/953, 35B, memo by Dr Sweeney to Dr Pincherle, 'Treatment of diabetic retinopathy', 20 September 1982.

99 TNA, final report, 'An investigation of the prevalence of diabetic retinopathy'.

100 Ibid., pp. 3-4 for raw figures, p. 1 for summaries.

101 Ibid., p. 10.

102 Ibid., pp. 9-10.

103 Ibid., pp. 11-13.

104 Ibid., pp. 13-14.

105 TNA, MH 150/953, 35A, memo by Dr Pincherle to Mr Saville, Dr Sweeney, Dr Ford, and Mr Ratcliffe, 'Treatment of diabetic retinopathy', 13 September 1982; TNA, memo by Dr Sweeney, 'Treatment of diabetic retinopathy'.

106 TNA, MH 150/953, 40A, memo by A. Burchell (Economic Advisers' Office, DHSS) to Dr Pincherle, 'Diabetic retinopathy', 6 December 1982. See also the attached paper, pp. 1-2.

107 S. Sheard, 'Space, place and (waiting) time: reflections on health policy and politics', Health Economics, Policy and Law, 13:3-4 (2018), 226-50. My thanks to Professor Sheard for allowing me advance access. Cf. J. Stanton, 'The cost of living: kidney dialysis, rationing and health 
economics in Britain, 1965-1996', Social Science \& Medicine, 49:9 (1999), 1169-82.

108 TNA, MH 150/953, 43C, meeting paper by Dr Pincherle, 'Diabetic retinopathy - screening and treatment', c. December 1982, p. 2.

109 TNA, MH 150/953, 43B, meeting note, 'Diabetic retinopathy', c.December 1982, pp. 1-2.

110 TNA, MH 150/953, 37C, memo by Mr Jewesbury, 'Centrally Reserved Funds', 20 October 1982.

111 TNA, MH 150/953, 47A, memo by T. J. Mathews to Dr Pincherle, 'Screening of diabetic retinopathy', 19 July 1983.

112 TNA, MH 150/953, 44A, cover note, 'Diabetic retinopathy', c.December 1982, p. 1.

113 TNA, MH 150/953, 66B, memo by T. E. Nodder to Mr Alcock on central funding bids, untitled, 21 March 1984, p. 3.

114 Ibid.

115 I. Kirkpatrick, S. Ackroyd, and R. Walker, The New Managerialism and Public Service Professions: Change in Health, Social Services and Housing (Basingstoke: Palgrave Macmillan, 2005), p. 52.

116 TNA, memo by Dr Sweeney to Dr Pincherle, 'Treatment of diabetic retinopathy'.

117 DHSS et al., Prevention and Health, pp. 71, 82.

118 TNA, memo by T. E. Nodder to Mr Alcock, p. 4.

119 TNA, cover note, 'Diabetic retinopathy', p. 2.

120 Addison, No Turning Back, pp. 279-84.

121 TNA, MH 150/953, 54D, minutes, 'Note of a meeting held on 22 August 1983', pp. 1-3.

122 Ibid., p. 1.

123 Ibid., pp. 1-3.

124 TNA, memo by T. E. Nodder to Mr Alcock; TNA, MH 150/953, 6/18, memo by Mr Alcock to Mr Nodder, 'Prevention of inherited disease; diabetic retinopathy screening', 10 April 1984.

125 M. J. Buxton, M. J. Sculpher, B. A. Ferguson, J. E. Humphreys, J. F. B. Altman, D. J. Spiegelhalter, A. J. Kirby, J. S. Jacob, H. Bacon, S. B. Dudbridge, J. W. Stead, T. G. Feest, H. Cheng, S. L. Franklin, P. Courtney, J. F. Talbot, R. Ahmed, and T. R. Dabbs, 'Screening for treatable diabetic retinopathy: a comparison of different methods', Diabetic Medicine, 8:4 (1991), 371-7.

126 Ibid., pp. 371-7, quotation at p. 376.

127 M. J. Buxton, M. J. Sculpher, B. A. Ferguson, J. E. Humphreys, J. F. B. Altman, D. J. Spiegelhalter, A. J. Kirby, J. S. Jacob, H. Bacon, S. B. Dudbridge, J. W. Stead, T. G. Feest, H. Cheng, S. L. Franklin, P. Courtney, J. F. Talbot, R. Ahmed, and T. R. Dabbs, 'A relative cost-effectiveness 
analysis of different methods of screening for diabetic retinopathy', Diabetic Medicine, 8:7 (1991), 644-50, quotation at p. 650.

128 P. M. Hart, D. B. Archer, and A. B. Atkinson, 'Diabetic patients should continue to be assessed by direct ophthalmoscopy', BMJ, 312:7047 (1996), 1670.

129 Klein, The New Politics of the NHS, pp. 133-5.

130 TNA, MH 150/953, memo by J. P. Cashman to Dr Halliday, 'Diabetic retinopathy screening, 68A, 14 May 1984.

131 TNA, MH 150/953, 70B, memo by N. P. Halliday to Mr Cashman, 'Screening for diabetic retinopathy', 15 May 1984; TNA, MH 150/953, 70C, memo by Dr Pincherle to Dr Halliday, 'Screening for diabetic retinopathy', 14 May 1984.

132 Hansard, HC, vol. 988, cols. 146-7W, 8 July 1980. 